\title{
Refractory Angina Cell Therapy (ReACT) Involving Autologous Bone Marrow Cells in Patients Without Left Ventricular Dysfunction: A Possible Role for Monocytes
}

\author{
Nelson Americo Hossne, Jr.,* Adriana Luckow Invitti, $\uparrow+$ Enio Buffolo,* Silvia Azevedo, $\dagger$ \\ José Salvador Rodrigues de Oliveira,§ Noedir Groppo Stolf,II L. Eduardo Cruz, $\dagger \neq$ and Paul R. Sanberg\# \\ *Cardiovascular Surgery Division, Surgery Department, Paulista School of Medicine, \\ Federal University of São Paulo, São Paulo, Brazil \\ $\nmid$ Cryopraxis Criobiologia Ltda, Rio de Janeiro, Brazil \\ \$Cellpraxis Bioengenharia, Rio de Janeiro, Brazil \\ §Hematology Division, Paulista School of Medicine, Federal University of São Paulo, São Paulo, Brazil \\ THeart Institute, College of Medicine, University of São Paulo, São Paulo, Brazil \\ \#Center of Excellence for Aging and Brain Repair, Department of Neurosurgery and Brain Repair, \\ College of Medicine, and Office of Research and Innovation, University of South Florida, Tampa, FL, USA
}

\begin{abstract}
Autologous bone marrow mononuclear cell (BMMC) transplantation has emerged as a potential therapeutic option for refractory angina patients. Previous studies have shown conflicting myocardium reperfusion results. The present study evaluated safety and efficacy of CellPraxis Refractory Angina Cell Therapy Protocol (ReACT), in which a specific BMMC formulation was administered as the sole therapy for these patients. The phase I/IIa noncontrolled, open label, clinical trial, involved eight patients with refractory angina and viable ischemic myocardium, without left ventricular dysfunction and who were not suitable for conventional myocardial revascularization. ReACT is a surgical procedure involving a single series of multiple injections (40-90 injections, $0.2 \mathrm{ml}$ each) into ischemic areas of the left ventricle. Primary endpoints were Canadian Cardiovascular Society Angina Classification (CCSAC) improvement at 18 months follow-up and myocardium ischemic area reduction (assessed by scintigraphic analysis) at 12 months follow-up, in correlation with a specific BMMC formulation. Almost all patients presented progressive improvement in angina classification beginning 3 months $(p=0.008)$ postprocedure, which was sustained at 18 months follow-up $(p=$ 0.004), as well as objective myocardium ischemic area reduction at 12 months (decrease of $84.4 \%, p<$ 0.004). A positive correlation was found between monocyte concentration and CCSAC improvement $(r=$ $-0.759, p<0.05)$. Improvement in CCSAC, followed by correlated reduction in scintigraphic myocardium ischemic area, strongly suggests neoangiogenesis as the main stem cell action mechanism. The significant correlation between number of monocytes and improvement strongly supports a cell-related effect of ReACT. ReACT appeared safe and effective.
\end{abstract}

Key words: Monocytes; Angina; Cell therapy; Bone marrow mononuclear cell transplantation; Myocardia; Ischemia

\section{INTRODUCTION}

Approximately 5-15\% patients with chronic coronary artery disease present severe disabling angina pectoris that cannot be controlled by a combination of conventional therapy tools, including multiple series of drug therapy optimization treatments, percutaneous transluminal coronary angioplasty (PTCA), and coronary artery bypass grafting (CABG) (21). Severe angina pectoris of- ten results in a substantial decrease in quality of life. Symptom relief for the "no option" refractory angina patient is a complex and challenging process. Alternative therapies in compliance with the American Heart Association Guidelines, such as surgical laser transmyocardial revascularization, external counterpulsation, and spinal cord stimulation, have all provided modest results at best $(13,16)$. The vast majority of refractory angina pectoris patients $(75 \%)$ have preserved left ventricular

Received July 13, 2009; final acceptance December 15, 2009. Online prepub date: December 18, 2009.

Address correspondence to Nelson Americo Hossne Jr., Canário St., 943-Ap. 123-Moema, São Paulo, São Paulo, Brazil 04521-004. Tel: +55-118166-5050; Fax: +55-11-5052-0386; E-mail: nelson.hossne@gmail.com 
function, with a mortality rate lower than the general coronary heart disease population (22), and this patient group is rapidly growing.

Cellular therapy, specifically autologous bone marrow cell transplantation, has emerged as a new therapeutic option for cardiac regeneration in both animal models $(14,17,42)$ and human studies $(23,26,29,34,37,41)$. Some hypothetical mechanistic explanations involve the stem cells' myogenic and angiogenic potential, and the activation of resident progenitor cell growth via paracrine effects $(2,9,36)$.

Although regeneration of myocardial tissue and concomitant reduction of the infarcted area have been demonstrated in experimental animal models, many uncertainties regarding the translation of these results into humans remain (33), rendering BMMC transplantation for cardiac tissue regeneration an experimental procedure, not a standard of care for clinical practice.

Nevertheless, refractory angina patients may benefit from cellular-based therapy, particularly in regards to angiogenesis. These angiogenic effects are considered among investigators to be very important when cell therapy is considered an option for human patients (19).

Angiogenic effects were reported in several preclinical studies $(6,19)$. Mobilization of mouse bone marrow (BM) cells (25) or sheep cord blood mononuclear cells (42) into the circulation after acute myocardial infarction resulted in regeneration of myocytes and vascular structures. This functional benefit in BM cell implantation is likely attributed to a paracrine effect with an increase in angiogenesis through local release of multiple growth factors, such as vascular endothelial growth factor and stromal cell-derived factor-1, among others (19).

In clinical studies involving refractory angina patients, who received bone marrow-derived stem cells or BMMC, improvement in symptoms and exercise capacity, as well as in myocardial perfusion were observed $(4,5,19,27,35)$. Beeres et al. (3) conducted a trial using intramyocardial injection of autologous BMMC in 25 patients with refractory angina, which showed sustained beneficial effects on anginal symptoms and myocardial perfusion. Losordo et al. (20) performed a phase I/IIa, double-blind, randomized, placebo-controlled dose-escalating clinical trial with endomyocardial injection of autologous $\mathrm{CD} 4^{+}$stem cells for refractory angina patients, demonstrating a trend of increased exercise time, in addition to Canadian Cardiovascular Society Angina Classification (CCSAC) improvement among CD34 ${ }^{+}$celltreated patients. van Ramshorst et al. (38) conducted a randomized controlled trial of intramyocardial bone marrow cell injection for refractory angina, with a shortterm follow-up (3-6 months) showing a modest improvement in myocardial perfusion compared with placebo.
Observing the minimal left ventricular improvement and the clinical response of previous refractory angina trials, it is suggested that the primary action of bone marrow stem cell transplantation in humans is promoting myocardial angiogenesis, and not pure myogenesis. In this setting, angiogenesis can surely improve left ventricular function through rescuing or recruiting hibernating myocardium, but to a limited extent, as demonstrated by these trials and some meta-analysis $(1,18)$.

Previous preclinical and clinical studies have supported the feasibility, safety, and efficacious potential of stem cell therapy for myocardium tissue regeneration and encompasses patients presenting with a range of diagnoses from acute myocardial infarction to chronic ischemic heart disease $(6,23,34,37,41)$.

The greatest challenge here consists in translating laboratory results to a standard clinical procedure. Differences in study design, stem and mononuclear cell preparation, and infusion techniques have delivered somewhat promising, but overall inconsistent, data from different studies (31).

The aim of our study was to evaluate the safety and efficacy of a proprietarily designed protocol, the CellPraxis Refractory Angina Cell Therapy Protocol (ReACT), in which a single series of multiple intramyocardial injections of a specific BMMC formulation is performed as the sole surgical therapy for these patients.

ReACT was designed in compliance with Good Manufacturing Practices (GMP) and FDA standards criteria.

Inclusion criteria for this study required patients diagnosed with refractory angina pectoris, with viable myocardium (diagnosed through stress tecnecium scintigraphy), without left ventricular dysfunction (ejection fraction of at least $45 \%$ ) and who were not suitable for myocardial revascularization (either PTCA or CABG).

Eight refractory angina patients were included in the study from September 2005 to July 2007. All patients had previously undergone surgical revascularization [once (four patients), twice (three patients), or four (one patient) times] without angina relief. Patients' baseline characteristics are described on Table 1.

An additional four refractory angina patients were enrolled and underwent ReACT, but required simultaneous coronary artery bypass grafting and were excluded from this analysis. These patients are currently being followed as a separate group.

\section{MATERIALS AND METHODS}

\section{Study Design/Study Population}

The study was a phase I/IIa noncontrolled open label clinical trial. Refractory angina patients routinely undergoing treatment at the São Paulo Hospital, in São Paulo, Brazil, a referral tertiary Federal University Hospital for 
coronary heart disease, were included in the study. The study protocol (ReACT) was approved by our local and national ethical committee (CEP-EPM-0314/05), and all patients provided written informed consent. Refractory angina patients were defined as those with functional class IV (angina at rest) according to the CCSAC despite maximum medical therapy, not suitable for conventional myocardial revascularization and with viable myocardium identification. Ineligibility for revascularizationeither percutaneous or surgical — was determined by at least two cardiologists and two cardiovascular surgeons based on the most recent (within 6 months) patient's coronary angiogram. Exclusion criteria were: (a) left ventricular ejection fraction (LVEF) $<45 \%$ on transthoracic echocardiogram; (b) absence of viable myocardium on cardiac nuclear imaging test; (c) positive serologic tests for human immunodeficiency virus (HIV), types $\mathrm{A}, \mathrm{B}$, and $\mathrm{C}$ hepatitis, human T-cell lymphotropic virus (HTLV), or Chagas disease; (d) significant heart valve disease; (e) chronic renal disease in dialysis; (f) abusive use of alcohol and drugs; (g) any other medical condition with estimated survival $<5$ years; (h) participation in prior cell therapy studies; and (i) pregnancy.

\section{Study Procedures}

For each patient, a total of $100 \mathrm{cc}$ of bone marrow was aspirated from the iliac crest, and stored in a saline solution of $80 \mathrm{IU}$ heparin/ml. Mononuclear cells were isolated by density gradient, and diluted to a final concentration of $10^{7}$ cells $/ \mathrm{ml}$, in accordance with ReACT and GMP. Cell viability, total mononuclear, leukocyte differential counting (including monocytes concentration), and $\mathrm{CD} 4^{+}$content, as well as aerobe and anaerobe microbiology tests, were performed. Samples for future evaluation were stored. One series of multiple cell formulation injections into the left ventricular myocardium were performed surgically, through a left lateral thoracotomy, as follows: $0.2 \mathrm{ml}\left(2 \times 10^{6}\right.$ cells $) /$ injection, $1 \mathrm{~cm}$ distance between injections, and $1 \mathrm{~cm}$ epimyocardial depth infusion. The number of injections (40-90) for each patient differed based on the extension of myocardium viable ischemic area determined on nuclear imaging tests, and left ventricular chamber size.

Follow-up

Patients' heart rhythm was monitored for $48 \mathrm{~h}$ after surgery. Clinical evaluation of CCSAC was carried out at months 3, 6, 12, and 18 after surgery. Echocardiogram was performed at baseline (prior to patient inclusion) and $1,3,6$, and 12 months and magnetic resonance (MR) of the heart at baseline and months 6 and 12 to assess safety. Nuclear imaging test (tecnecium stress-induced myocardium perfusion scintigraphy) was performed at baseline and 6 and 12 months after the procedure to evaluate the percentage of myocardium ischemic area. It is important to point out, regarding ischemic heart area objective analysis (stress scintigraphy), that all patients were considered to have $100 \%$ of viable myocardium ischemic area on those specific left ventricular walls identified by stress tecnecium scintigraphy, prior to cell formulation injection. These reversible ischemic heart areas were considered baseline comparison to 6 and 12 months scintigraphic analysis follow-up. Scintigraphic analysis was only performed at 6 and 12 months follow-up.

\section{Statistical Analysis}

The Friedman nonparametric test was used to assess changes from baseline in angina CCSAC class at 3,6, and 12 months and in myocardium ischemic area at 6

Table 1. Patients' Baseline Characteristics

\begin{tabular}{lclccccc}
\hline Patient & Age & Gender & Diabetes & $\begin{array}{c}\text { Drug } \\
\text { Therapy } \\
\text { Optimization }\end{array}$ & $\begin{array}{c}\text { Ejection } \\
\text { Fraction }\end{array}$ & $\begin{array}{c}\text { Previous } \\
\text { CABG }(n)\end{array}$ & CCSAC \\
\hline 1 & 62 & male & yes & yes & $63 \%$ & yes (1) & 4 \\
2 & 70 & male & no & yes & $63 \%$ & yes (2) & 4 \\
3 & 58 & male & no & yes & $74 \%$ & yes (2) & 4 \\
4 & 72 & female & yes & yes & $59 \%$ & yes (2) & 4 \\
5 & 75 & male & yes & yes & $56 \%$ & yes (1) & 4 \\
6 & 79 & male & yes & yes & $61 \%$ & yes (1) & 4 \\
7 & 53 & male & no & yes & $47 \%$ & yes (4) & 4 \\
8 & 53 & female & yes & yes & $62 \%$ & yes (1) & 4 \\
\hline
\end{tabular}

Drug therapy optimization is defined as repeated attempts of drug therapy optimization and combination, including maximum dosage of beta blockers, angiotensin converting enzyme inhibitors, calcium channel blockers, short- and long-lasting action nitrates, statins, and antiplatelets, for at least 3 months prior to patient meeting inclusion criteria. 


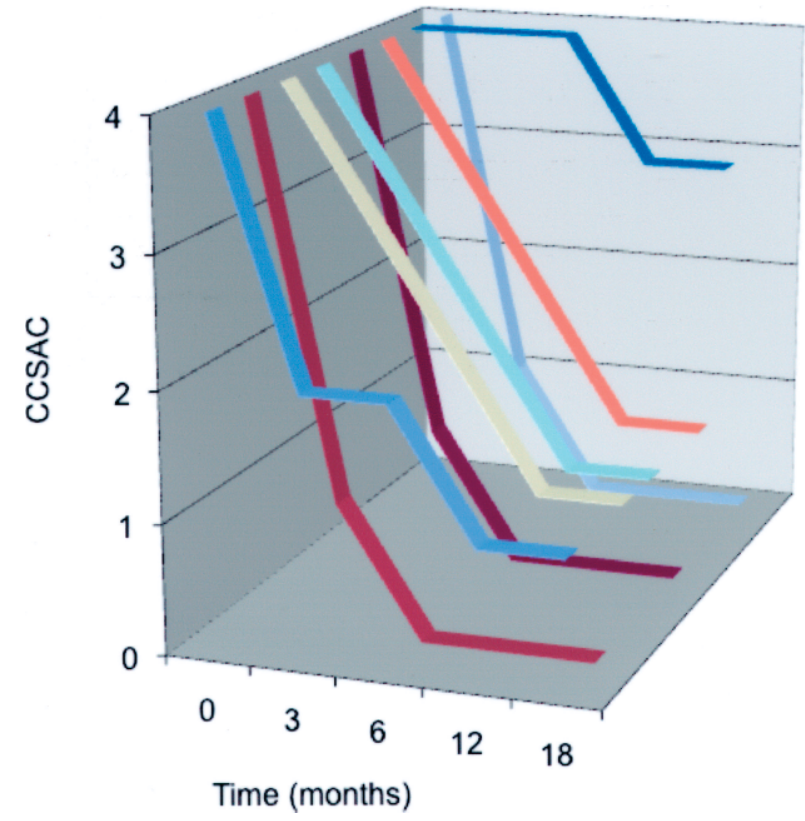

Figure 1. Variations in CCSAC over 18 months follow-up. Each line in the graphic represents one patient enrolled in Re$\mathrm{ACT}$ and the corresponding CCSAC improvement over the 18-month follow-up. The $x$-axis represents CCSAC class (number 4 for refractory angina pectoris, and number 0 for no pain). The $y$-axis represents patient follow-up in months. Onetailed Wilcoxon test statistical analysis of CCSAC improvement was significant at 3 (0.008), 6 (0.008), $12(0.004)$, and 18 (0.004) months follow-up compared to baseline; variation in angina class is statistically significant if $p<0.0125(0.05 / 4)$ (Bonferroni's correction). and 12 months of follow-up. For post hoc comparisons, the Wilcoxon test with Bonferroni's correction was used. Correlation between outcomes (angina class and myocardium ischemic area after the procedure) and the injections number was assessed by Spearman test. To compare the left ventricular function on echocardiogram before and at 12 months after the procedure, the Wilcoxon nonparametric test was used.

\section{RESULTS}

\section{Subjective Improvement in Myocardial Ischemia}

After the ReACT myocardial injection procedure, there was a progressive improvement in the angina classification median, varying from class 4 at baseline to 2.3 ( $p=0.008), 1.5(p=0.008), 0.9(p=0.004)$, and $0.9(p=$ $0.004)$ at $3,6,12$, and 18 months of follow-up, respectively (Fig. 1, Table 2).

\section{Objective Improvement in Myocardial Ischemia}

A progressive reduction in ischemic myocardium area was observed by stress tecnecium scintigraphy after 6 months (decrease of $39.4 \%, p=0.06$ ) and 12 months (decrease of $84.4 \%, p<0.004$ ), although the difference was statistically significant only at 12 months. It is important to note that all patients were considered to have $100 \%$ of viable myocardium ischemic area on those specific left ventricular walls identified by stress tecnecium scintigraphy, prior to cell formulation injection. These initial reversible ischemic heart areas were considered baseline when compared to 6 and 12 months scintigraphic analysis follow-up (Fig. 2, Fig. 3, Table 2).

Table 2. Variation in Angina Classification and Myocardium Ischemic Area After the ReACT Infusion

\begin{tabular}{|c|c|c|c|c|c|c|c|c|}
\hline \multirow[b]{2}{*}{ Patient } & \multicolumn{5}{|c|}{ Canadian Cardiovascular Society Angina Classification $(p<0.001)$} & \multicolumn{3}{|c|}{$\%$ Ischemic Area* $(p<0.002)$} \\
\hline & Pre & 3 Months & $\begin{array}{c}6 \text { Months } \\
\text { of Follow-up }\end{array}$ & $\begin{array}{l}12 \text { Months } \\
\text { of Follow-up }\end{array}$ & $\begin{array}{l}18 \text { Months } \\
\text { of Follow-up }\end{array}$ & Pre† & $\begin{array}{c}6 \text { Months } \\
\text { of Follow-up }\end{array}$ & $\begin{array}{l}12 \text { Months } \\
\text { of Follow-up }\end{array}$ \\
\hline 1 & 4 & 2 & 2 & 1 & 1 & 100 & 0 & 0 \\
\hline 2 & 4 & 1 & 0 & 0 & 0 & 100 & 0 & 0 \\
\hline 3 & 4 & 3 & 2 & 1 & 1 & 100 & 0 & 0 \\
\hline 4 & 4 & 3 & 2 & 1 & 1 & 100 & 100 & 0 \\
\hline 5 & 4 & 1 & 0 & 0 & 0 & 100 & 100 & 40 \\
\hline 6 & 4 & 3 & 2 & 1 & 1 & 100 & 100 & 0 \\
\hline 7 & 4 & 4 & 4 & 3 & 3 & 100 & 85 & 85 \\
\hline 8 & 4 & 1 & 0 & 0 & 0 & 100 & 100 & 0 \\
\hline Mean & 4 & 2.3 & 1.5 & 0.9 & 0.9 & 100 & 60.6 & 15.6 \\
\hline Median & 4 & 2.5 & 2.0 & 1.0 & 1.0 & 100 & 92.5 & 0.0 \\
\hline \multicolumn{9}{|l|}{$p$-Value (unilateral } \\
\hline Wilcoxon test) $\ddagger$ & & 0.008 & 0.008 & 0.004 & 0.004 & & 0.063 & 0.004 \\
\hline
\end{tabular}

*Assessed by stress tecnecium scintigraphy.

$\dagger$ All patients were considered to have $100 \%$ of viable myocardium ischemic area on those specific left ventricular walls identified by stress tecnecium scintigraphy, prior to cell formulation injection. The 6- and 12-month analysis reflects the myocardium ischemic area percentage reduction on these walls.

$\ddagger$ Related to baseline; variation in angina class and ischemic myocardium area statistically significant if $p<0.0125(0.05 / 4)$ and $p<0.025(0.05 / 2)$ (Bonferroni's correction), respectively. 


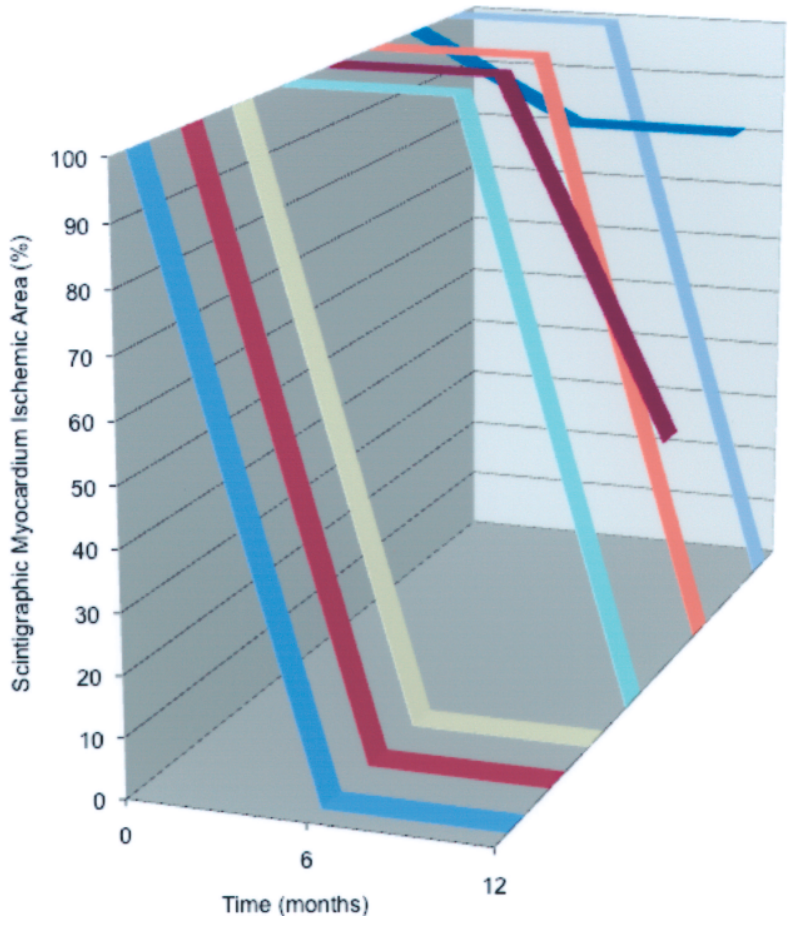

Figure 2. Variations in myocardial ischemic area evaluated by stress tecnecium scintigraphy at 12 months follow-up. Each line in the graphic represents one patient enrolled in ReACT and the corresponding scintigraphic myocardium ischemic area improvement over 12 months follow-up. The $x$-axis represents the percentage of scintigraphic myocardial ischemic area. The $y$-axis represents patient follow-up in months (scintigraphic analysis was assessed only at 6 and 12 months). Onetailed Wilcoxon test statistical analysis of scintigraphic myocardium ischemic area improvement was not significant at 6 (0.063) but was significant at $12(0.004)$ months follow-up compared to baseline; variation in scintigraphic myocardium ischemic area improvement is statistically significant if $p<$ $0.025(0.05 / 2)$ (Bonferroni's correction).

\section{Correlation Between ReACT's Formulation and Improvement}

ReACT has a certain percentage of monocytes $(12.4$ \pm 3.5 ; range 8.0-18.4) (see Table 1 for more details) and its specific formulation positively correlates with clinical response: specifically, improvement in CCSAC (Table 4, Fig. 4).

Other cell types such as lymphocytes or $\mathrm{CD} 34^{+}$cells showed no correlation with CCSAC or myocardium ischemic area improvement.

\section{Correlation Between Number of Myocardium Punctures and Improvement}

The number of myocardium punctures varied from 40 to 90 in each patient $(58 \pm 14.9)$, depending on the extent of the left ventricular ischemic area, as determined by stress tecnecium scintigraphy. No significant correlation was found between the number of punctures (the "act of introducing the needle" into the heart muscle) and angina classification improvement at 3, 6, 12, and 18 months. Also, there was no correlation between the number of punctures and changes in ischemic myocardium area at 6 and 12 months of follow-up, as shown in Table 5 and Figures 5 and 6.

\section{Left Ventricular Ejection Fraction}

The difference in LVEF median assessed by echocardiogram was not statistically significant, according to Wilcoxon test, varying from $60.6 \pm 7.6 \%$ at baseline to $61.1 \pm 6.5 \%$ at 12 months follow-up ( $p=0.726$ ) (see Fig. 7).

\section{Safety}

None of the patients presented arrhythmia, or local (as assessed by heart magnetic resonance imaging) or systemic neoplasia up to 18 months after the procedure.

\section{DISCUSSION}

The results of this study demonstrate that ReACT may benefit refractory angina patients, who are not suitable for conventional myocardial revascularization, and show signs of angina at rest despite maximum medical therapy. Our findings demonstrate an improvement in angina symptoms and a decrease in the extent of myocardial ischemia. The probable causal mechanism of this improvement may be angiogenic properties of ReACT formulation.

In our study, angina symptom relief began as early as 3 months postprocedure with continuing improvement through 12 months and sustained improvement through 18 months, suggesting that angiogenesis began early, and that it kept evolving 18 months after the procedure (see Table 2 and Fig. 1). Furthermore, symptom relief progressively improved in all patients, suggesting that the effect is sustained and not transitory, a result different from other studies (5). Accordingly, the myocardial ischemia area percentage showed a decreasing trend, ultimately reaching significance at 12 months. The fact that symptom improvement occurred much earlier than perfusion improvement might be explained by nuclear imaging testing's low spatial resolution and high variability, preventing it from detecting small changes, especially in such a small patient population.

The natural history of refractory angina shows that spontaneous remissions of even severe angina may occur $(16,22,30)$. Looking at medically treated groups of randomized studies at 12 months posttreatment, up to $19 \%$ of patients included in percutaneous myocardial laser revascularization trials and up to $32 \%$ of patients (and up to $44 \%$ at 36 months) for surgical myocardial laser revascularization studies had an improvement of at 


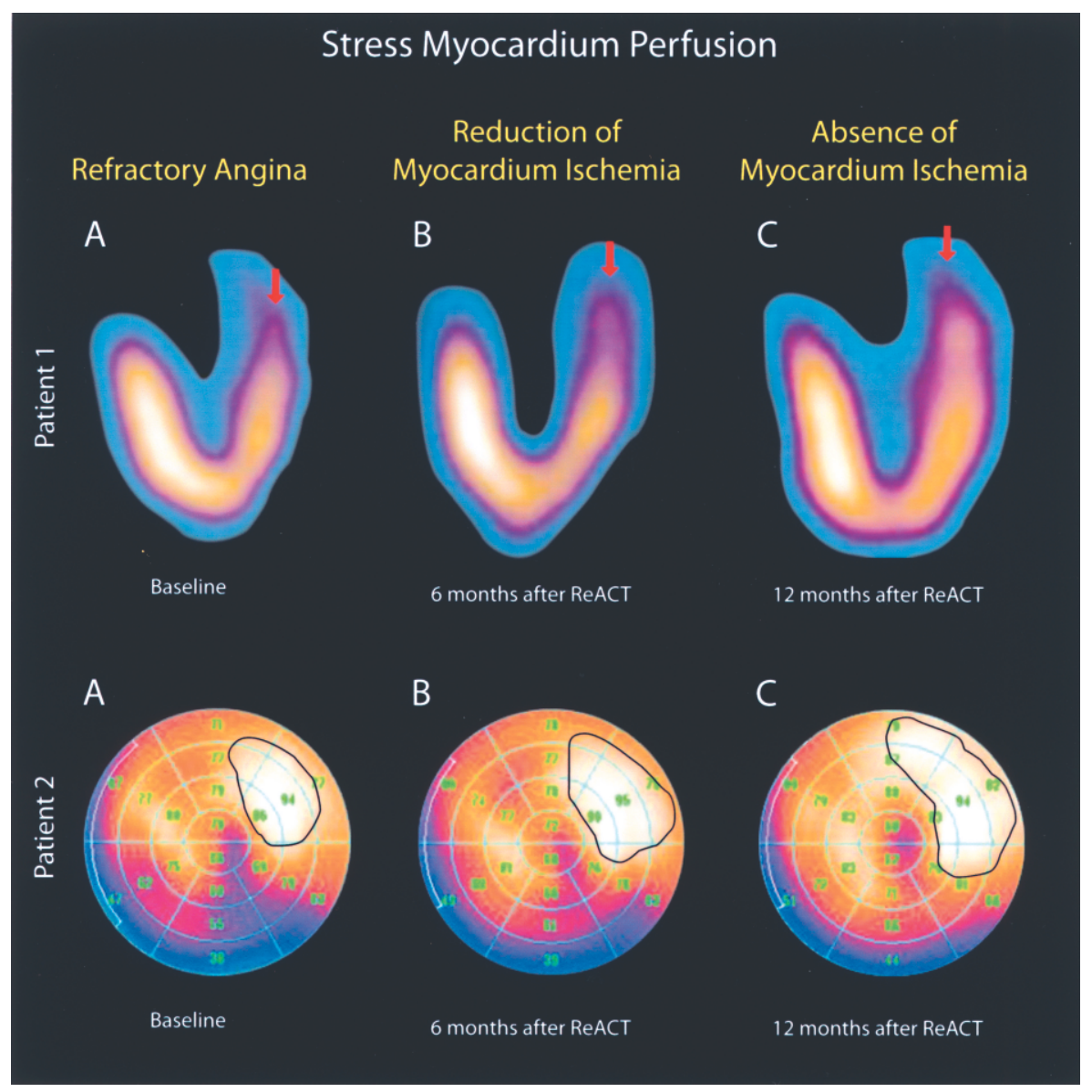

Figure 3. Comparison between the scintigraphic myocardium stress perfusion area from baseline to 6 and 12 months after ReACT procedure, in two patients. (A) Refractory angina, at baseline. (B) Reduction of myocardium ischemic area. (C) Absence of myocardium ischemic area.

least two points in CCSAC (24). Our results show a much compelling and greater CCSAC improvement, reinforced by the tangible myocardium perfusion stress testing.

Refractory angina studies include mainly patients with moderate to severe left ventricular dysfunction. As a result, our study showed better improvement in angina symptoms and quality of life, rather than benefits in left ventricular ejection fraction (LVEF). In our study, all patients had LVEF $\geq 45 \%$ at baseline and, as expected, there was no significant change in LVEF at 12 months $(p=0.726)$. These findings also suggest angiogenesis directly related to stem cell infusion and not myocardial punctures promoting secondary angiogenesis. On the other hand, the sustained LVEF as well as the myocardial perfusion improvement suggests absence of functional deficit due to myocardium necrosis or fibrosis promoted by the intramyocardial ReACT injections, reinforcing the procedure safety.

The standard refractory angina patient population with viable myocardium and preserved left ventricular function would be the ideal candidate for an angiogenic therapy employing ReACT intramyocardial injection. For obvious reasons, analysis of LVEF is not an endpoint for this group. The primary therapeutic goal is myocardial perfusion improvements using ReACT formulation in a subjective (CCSAC) and objective (stressinduced myocardium imaging testing) perspective.

Different from other studies, ReACT has a specific cell formulation, which seems to correlate with clinical and scintigraphic responses: an improvement in angina classification and a reduction in myocardium ischemic area, respectively. Improvement in CCSAC (subjective measure), followed by correlated reduction in myocardium ischemic area (objective measure), strongly suggests neoangiogenesis as the main stem cell action mechanism (Figs. 1 and 2). Consequently, the large fraction of monocytes present in ReACT seems to be related to the angiogenesis that restores the perfusion of the myocardial ischemic areas after the cell transplantation. 
Table 3. Percentage of Monocyte Concentration in ReACT in Each Patient

\begin{tabular}{lc}
\hline Patient & Monocyte Concentration \\
\hline 1 & - \\
2 & 18.36 \\
3 & 11.20 \\
4 & 13.92 \\
5 & 14.47 \\
6 & 9.52 \\
7 & 7.99 \\
8 & 11.20 \\
\hline
\end{tabular}

Please note that monocyte data for patient number 1 are not available.

The mechanisms are not yet elucidated and will be analyzed in the next phase of this study. Nevertheless, a significant correlation between number of monocytes and improvement of clinical response $(r=-0.759, p<$ $0.05)$ strongly supports a cell related effect of ReACT in this study.

This positive correlation between the number of monocytes in ReACT and the sustained improvement in angina class could indicate the importance of these supporting cells for BMMC mechanism of action and sustained myocardium angiogenesis. The importance of monocytes in the transplantation of mononuclear cells has also been shown in the treatment of stroke $(39,40)$. Also critical, these data support the hypothesis that the results of this study are due to a cellular effect of ReACT formulation and not to nonspecific effects of the ReACT procedure. Future controlled studies will further clarify.

Bone marrow is a natural source of a broad spectrum of cytokines that are involved in the control of angiogenic and inflammatory processes. Bone marrow leukocytes play an important role in the angiogenic mechanism, and neutrophils and monocytes act as a key in this process $(12,15)$.

Monocytes/macrophages essentially contribute to neovascularization in heart and other ischemic diseases, regardless of the mechanism involved (either arteriogenesis or angiogenesis) $(11,32)$.

When arteriogenesis is the main process, monocytes can promote endothelial and smooth muscle cell proliferation, through a significant increase in monocyte chemotactic protein-1 (MCP-1) (32).

In angiogenesis, VEGF and angiopoietin induce the recruitment of endothelial progenitor cells and monocytes/macrophages. These recruited monocytes/macrophages promote angiogenesis by several potential mechanisms, including endothelial cell migration, proliferation or tube formation, growth factors mobilization, proangiogenic cytokines release, and transdifferentiation into endothelial-like cells. Furthermore, the endothelial cell production of MCP-1, VEGF, and angiopoietin initiated by VEGF exposure or hypoxia activate and attract more monocytes/macrophages, resulting in an auto feedback of the angiogenic process (32).

The optimal number or formulation of stem cells to promote myocardial regeneration remains controversial among different investigators, most of them showing no dose-dependent effect $(7,8)$.

Henning et al. (10) injected human cord bloodderived bone marrow stem cells in infarcted rats, comparing different doses and routes of administration (intramyocardial, intracoronary, or intravenous), demonstrating higher effectiveness with the intramyocardial injection. In our study, we performed ReACT, a single series of multiple injections with $2 \times 10^{6} \mathrm{BMMC}$ formulation/myocardium puncture. There was no correlation between the number of injections and the angina classification variation over time; however, the study population was probably too small for any significant association to be reached and as the ReACT protocol is designed to continue, future data may or may not confirm this.

The intramyocardial route of cell formulation delivery was selected based upon experimental data that shows higher myocardial stem cell uptake through intramyocardial infusion, in comparison to other routes, such as intracoronary (either anterograde or retrograde injection) or transcoronary $(6,10,28)$. Also, the chronic clinical feature of refractory angina provides a much safer profile for an intramyocardial approach, without major complication concerns, like intramyocardial injection in the acute setting (acute myocardial infarction).

It is important to point out that, although promising, we understand our study has some limitations. While our study included a larger number of patients with a significantly greater follow-up time than most published refractory angina studies, the small sample size of eight patients makes efficacy determination difficult, but has been able to demonstrate safety. Due to ethical aspects and the inability to justify the use of an isolated surgical intramyocardial placebo in this population, this was a nonrandomized, open study; consequently, a placebo effect cannot be ruled out. However, it should be emphasized that an objective increase in myocardium perfusion was also assessed and maintained over time.

Other clinical studies still need to confirm our results. However, the effectiveness of this ReACT procedure, in compliance with the technical and GMP specifications as well as a specific cell preparation of ReACT, seem to deliver better outcomes than previously reported by other investigators.

In conclusion, surgical intramyocardial transplantation of an autologous, bone marrow-derived cell prepa- 
Table 4. Spearman's Correlation Coefficients $\left(r_{\mathrm{s}}\right)$ Between ReACT Monocyte

Content, Lymphocytes, and CD34 ${ }^{+}$Cells and Improvement of Angina

Classification and Percent Myocardium Ischemic Area in the Follow-up

\begin{tabular}{lccr}
\hline & Monocytes & Lymphocytes & CD 34 \\
\hline Angina class: 3 months follow-up $(n=7)$ & & & \\
$\quad r_{\mathrm{s}}$ & -0.759 & 0.579 & -0.318 \\
$\quad p$-Value & 0.048 & 0.174 & 0.487 \\
Angina class: 6 months follow-up $(n=7)$ & & & \\
$\quad r_{\mathrm{s}}$ & -0.759 & 0.579 & -0.458 \\
$\quad p$-Value & 0.048 & 0.174 & 0.301 \\
Angina class: 12 months follow-up $(n=7)$ & & & \\
$\quad r_{\mathrm{s}}$ & -0.759 & 0.579 & -0.458 \\
$\quad p$-Value & 0.048 & 0.174 & 0.301 \\
Angina class: 18 months follow-up $n=7)$ & & & \\
$\quad r_{\mathrm{s}}$ & -0.759 & 0.579 & -0.458 \\
$\quad p$-Value & 0.048 & 0.174 & 0.301 \\
$\%$ Ischemic area: 6 months follow-up $(n=7)$ & & & \\
$\quad r_{\mathrm{s}}$ & -0.101 & 0.339 & 0.077 \\
$p$-Value & 0.830 & 0.457 & 0.869 \\
$\%$ Ischemic area: 12 months follow-up $(n=7)$ & & & \\
$\quad r_{\mathrm{s}}$ & -0.270 & 0.267 & -0.204 \\
$p$-Value & 0.559 & 0.562 & 0.661 \\
\hline
\end{tabular}

For technical reasons, we do not have cell counting and percentage for the first patient enrolled in the study; therefore, analysis is only seven patients. Angina class was assessed according to Canadian Cardiovascular Society Angina Classification. Percent ischemic area improvement assessed by stress tecnecium scintigraphy.

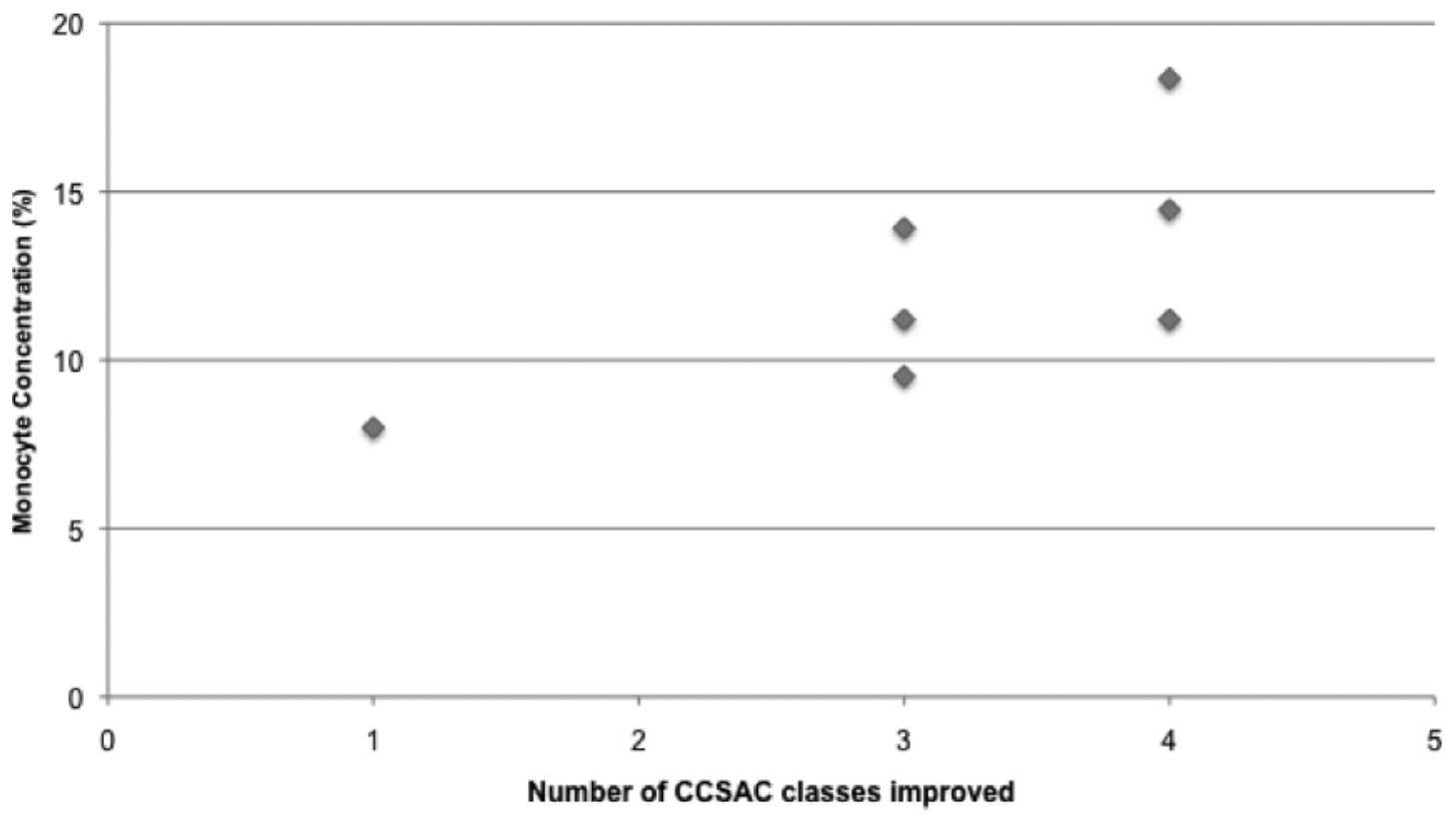

Figure 4. Correlation between monocyte concentration in ReACT and CCS improvement in 18 months follow-up. Each point represents one patient. The $x$-axis corresponds to the monocyte concentration and the $y$-axis corresponds to number of CCS classes improved. 
Table 5. Spearman's Correlation Coefficients $\left(r_{\mathrm{s}}\right)$ Between Number of Punctuations and Results of CCSAC and Percent Myocardium Ischemic Area Improvement During Follow-up

\begin{tabular}{lcccccc}
\hline & Angina & Angina & Angina & Angina & \% Ischemic & \% Ischemic \\
& Class: & Class: & Class: & Class: & Area: & $\begin{array}{c}\text { Area: } \\
\text { Injections }\end{array}$ \\
& 3 Months & 6 Months & 12 Months & 18 Months & 6 Months & 12 Months \\
& Follow-up & Follow-up & Follow-up & Follow-up & Follow-up & Follow-up \\
\hline$r_{\mathrm{s}}$ & -0.403 & -0.216 & -0.216 & -0.216 & -0.203 & -0.204 \\
$p$-Value & 0.322 & 0.607 & 0.607 & 0.607 & 0.629 & 0.628 \\
\hline
\end{tabular}

Angina class assessed according to Canadian Cardiovascular Society Angina Classification. Percent ischemic area improvement as assessed by stress tecnecium scintigraphy. $N=8$ for all.

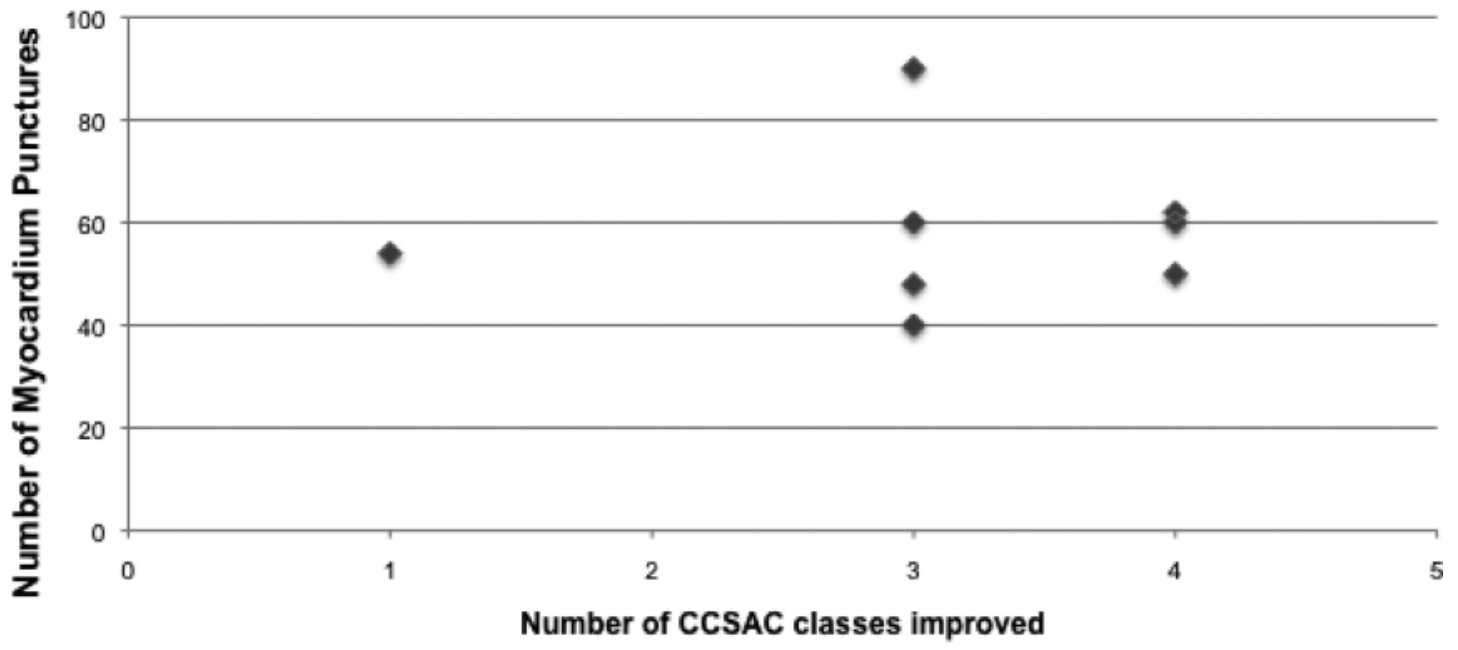

Figure 5. Correlation between number of myocardium punctures and CCS improvement in 18 months follow-up. Each point in the graphic represents one patient. The $x$-axis corresponds to the number of myocardium punctures and the $y$-axis corresponds to number of CCS classes improved.

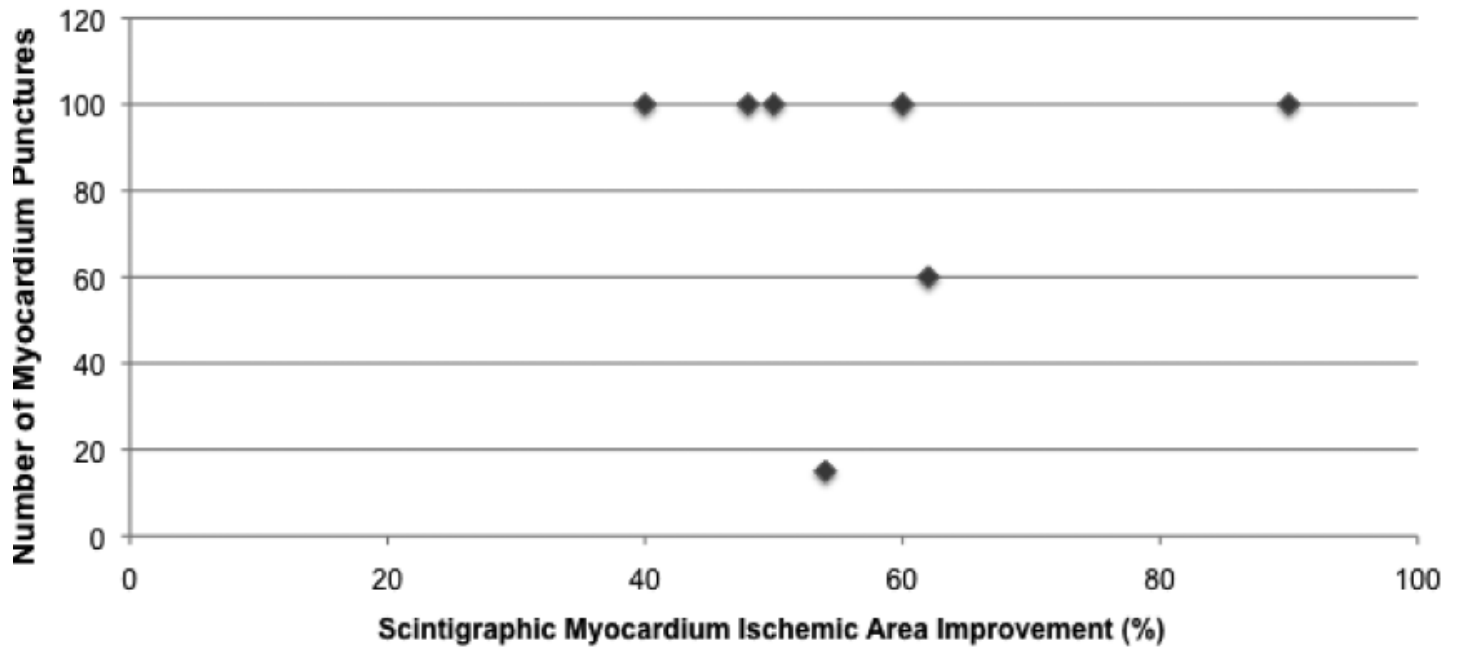

Figure 6. Correlation between number of myocardium punctures and myocardium ischemic area reduction, as assessed by stress scintigraphy. Each point in the graphic represents one patient. The $x$-axis corresponds to the number of myocardium punctures and the $y$-axis corresponds to percentage of myocardium ischemic area improved. 


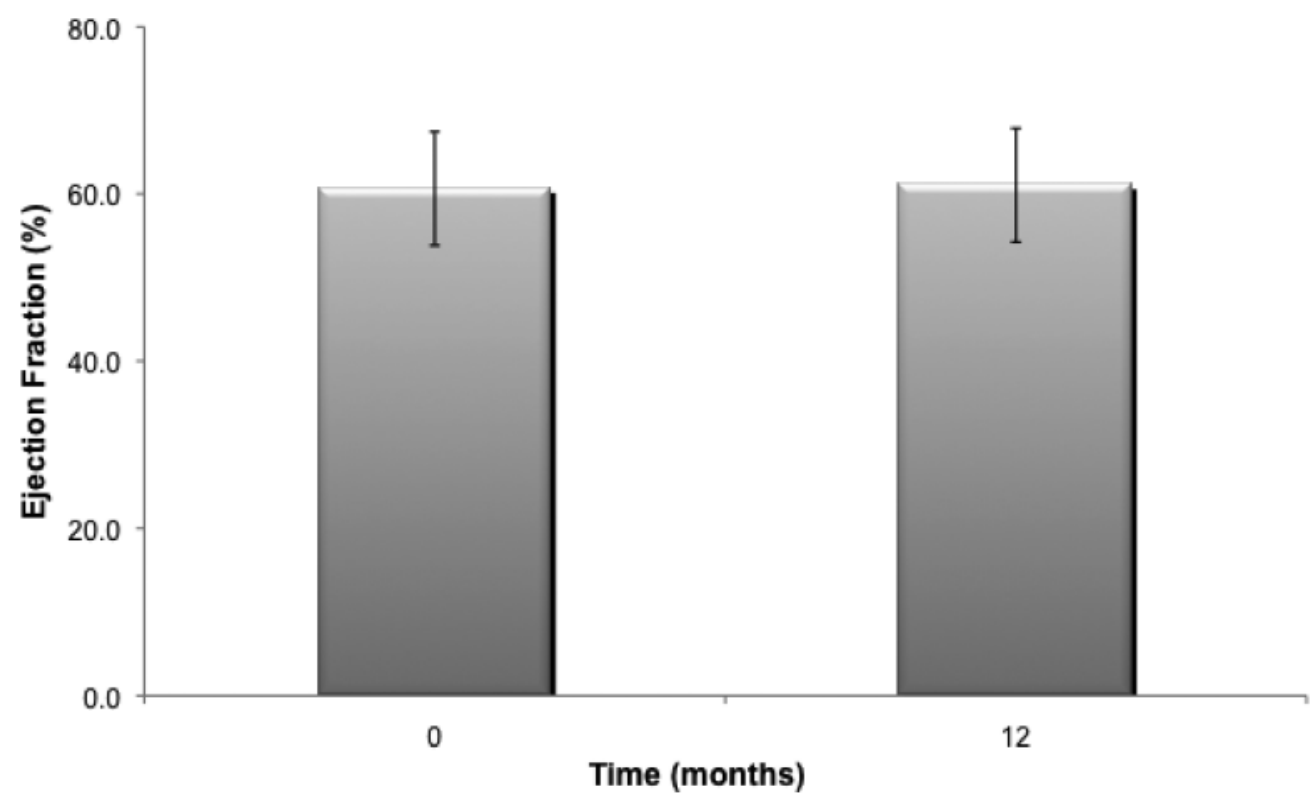

Figure 7. Comparison between left ventricular ejection fraction, as assessed by transthoracic echocardiogram, at baseline and 12 months follow-up. The left bar represents baseline left ventricular ejection fraction, while the right one represents the ejection fraction at 12 months. The $x$-axis corresponds to echocardiographic left ventricular ejection fraction (in \%) and the $y$-axis corresponds to time point, in months (where $0=$ baseline).

ration, in a standardized protocol, may be a safe and effective procedure in promoting progressive and sustained improvement in patients with refractory angina.

ACKNOWLEDGMENTS: We wish to thank Dong-Hyuk Park, David Eve, and Nicole Kuzmin-Nichols for revisions. We also wish to thank Cryopraxis Crobiologia Ltda. and Cellpraxis Biogenharia for grant support and funding. Dr. Amit Patel, Cardiovascular Systems Section Editor, handled all editorial peer review, determination of reviewers, and final acceptance of this article in a blinded fashion to all authors. N.A.H., A.L.I., and P.R.S. are inventors on a patent application submitted in regards to the technology related to this article. N.A.H. and P.R.S. are consultants for Cryopraxis. ReACT TM is a trademark licensed to Cryopraxis.

\section{REFERENCES}

1. Abdel-Latif, A.; Bolli, R.; Tleyjeh, I. M.; Montori, V. M.; Perin, E. C.; Hornung, C. A.; Zuba-Surma, E. K.; AlMallah, M.; Dawn, B. Adult bone marrow-derived cells for cardiac repair. A systematic review and meta-analysis. Arch. Intern. Med. 167:989-997; 2007.

2. Anversa, P.; Leri, A.; Rota, M.; Hosoda, T.; Bearzi, C.; Urbanek, K.; Kajstura, J.; Bolli, R. Concise review: Stem cells, myocardial regeneration, and methodological artifacts. Stem Cells 25:589-601; 2007.

3. Beeres, S. L.; Bax, J. J.; Dibbets-Schneider, P.; Stokkel, M. P.; Fibbe, W. E.; van der Wall, E. E.; Schalij, M. J.; Atsma, D. E. Sustained effect of autologous bone marrow mononuclear cell injection in patients with refractory angina pectoris and chronic myocardial ischemia: Twelvemonth follow-up results. Am. Heart J. 152:684.e11-16; 2006.
4. Beeres, S. L.; Bax, J. J.; Kaandorp, T. A.; Zeppenfeld, K.; Lamb, H. J.; Dibbets-Schneider, P.; Stokkel, M. P.; Fibbe, W. E.; de Roos, A.; van der Wall, E. E.; Schalij, M. J.; Atsma, D. E. Usefulness of intramyocardial injecton of autologous bone marrow-derived mononuclear cells in patients with severe angina pectoris and stress-induced myocardial ischemia. Am. J. Cardiol. 97:1326-1331; 2006.

5. Briguori, C.; Reimers, B.; Sarais, C.; Napodano, M.; Pascotto, P.; Azzarello, G.; Bregni, M.; Porcellini, A.; Vinante, O.; Zanco, P.; Peschle, C.; Condorelli, G.; Colombo, A. Direct intramyocardial percutaneous delivery of autologous bone marrow in patients with refractory myocardial angina. Am. Heart J. 151:674-680; 2006.

6. Charwat, S.; Gyöngyösi, M.; Lang, I.; Graf, S.; Beran, G.; Hemetsberger, R.; Nyolczas, N.; Sochor, H.; Glogar, D. Role of adult bone marrow stem cells in the repair of ischemic myocardium: Current state of the art. Exp. Hematol. 36:672-680; 2008.

7. Hale, S. L.; Dai, W.; Dow, J. S.; Kloner, R. A Mesenchymal stem cell administration at coronary artery reperfusion in the rat by two delivery routes: A quantitative assessment. Life Sci. 83:511-515; 2008.

8. Hashemi, S. M.; Ghods, S.; Kolodgie, F. D.; ParchamAzad, K.; Keane, M.; Hamamdzic, D.; Young, R.; Rippy, M. K.; Virmani, R.; Litt, H.; Wilensky, R. L. A placebo controlled, dose-ranging, safety study of allogenic mesenchymal stem cells injected by endomyocardial delivery after an acute myocardial infarction. Eur. Heart J. 29:251259; 2008.

9. Henning, R. J.; Abu-Ali, H.; Balis, J. U.; Morgan, M. B.; Willing, A. E.; Sanberg, P. R. Human Umbilical cord blood mononuclear cells for the treatment of acute myocardial infarction. Cell Transplant. 13:729-739; 2004.

10. Henning, R. J.; Burgos, J. D.; Vasko, M.; Alvarado, F.; 
Sanberg, C. D.; Sanberg, P. R.; Morgan, M. B. Human cord blood cells and myocardial infarction: Effect of dose and route of administration on infarct size. Cell Transplant. 16:907-917; 2007.

11. Hirose, N.; Maeda, H.; Yamamoto, M.; Hayashi, Y.; Lee, G-H.; Chen, L.; Radhakrishnan, G.; Rao, P.; Sasaguri, S. The local injection of peritoneal macrophages induces neovascularization in rat ischaemic hind limb muscles. Cell Transplant. 17:211-222; 2008.

12. Hoefer, I. E.; Grundmann, S.; van Royen, N.; Voskuil, M.; Schirmer, S. H.; Ulusans, S.; Bode, C.; Buschmann, I. R.; Piek, J. J. Leukocyte subpopulations and arteriogenesis: Specific role of monocytes, lymphocytes and granulocytes. Atherosclerosis 181:285-293; 2005.

13. Jolicoeur, E. M.; Granger, C. B.; Henry, T. D.; Holmes, D. J.; Pepine, C. J.; Mark, D.; Chaitman, B. R.; Gersh, B. J.; Ohman, E. M.; Working Group Members. Clinical and research issues regarding chronic advanced coronary artery disease: Part I: Contemporary and emerging therapies. Am. Heart J. 155:418-434; 2008.

14. Krausgrill, B.; Vantler, M.; Burst, V.; Raths, M.; Halbach, M.; Frank, K.; Schynkowski, S.; Schenk, K.; Hescheler, J.; Rosenkranz, S.; Müller-Ehmsen, J. Influence of cell treatment with PDGF-BB and reperfusion on cardiac persistence of mononuclear and mesenchymal bone marrow cells after transplantation into acute myocardial infarction in rats. Cell Transplant. 18(8):847-853; 2009.

15. Kusumanto, Y. H.; Dam, W. A.; Hospers, G. A. P.; Meijer, C.; Mulder, N. H. Platelets and granulocytes, in particular the neutrophils, form important compartments for circulating vascular endothelial growth factor. Angiogenesis 6:283-287; 2003.

16. Leon, M. B.; Kornowski, R.; Downey, W. E.; Weisz, G.; Baim, D. S.; Bonow, R. O.; Hendel, R. C.; Cohen, D. J.; Gervino, E.; Laham, R.; Lembo, N. J.; Moses, J. W.; Kuntz, R. E. A blinded, randomized, placebo-controlled trial of percutaneous laser myocardial revascularization to improve angina symptoms in patients with severe coronary disease. J. Am. Coll. Cardiol. 46:1812-1819; 2005.

17. Li, T. S.; Mikamo, A.; Takahashi, M.; Suzuki, R.; Ueda, K.; Ikeda, Y.; Matsuzaki, M.; Hamano, K. Comparison of cell therapy and cytokine therapy for functional repair in ischemic and nonischemic heart failure. Cell Transplant. 16(4):365-374; 2007.

18. Lipinski, M. J.; Biondi-Zoccai, G. G.; Abbate, A.; Khianey, R.; Sheiban, I.; Bartunek, J.; Vanderheyden, M.; Kim, H. S.; Kang, H. J.; Strauer, B. E.; Vetrovec, G. W. Impact of intracoronary cell therapy on left ventricular function in the setting of acute myocardial infarction: A collaborative systematic review and meta-analysis of controlled clinical trials. J. Am. Coll. Cardiol. 50:1761-1767; 2007.

19. Losordo, D. W.; Renault, M. A. Therapeutic myocardial angiogenesis. Microvasc. Res. 74:159-171; 2007.

20. Losordo, D. W.; Schatz, R. A.; White, C. J.; Udelson, J. E.; Veereshwarayya, V.; Durgin, M.; Poh, K. K.; Weinstein, R.; Kearney, M.; Chaudhry, M.; Burg, A.; Eaton, L.; Heyd, L.; Thorne, T.; Shturman, L.; Hoffmeister, P.; Story, K.; Zak, V.; Dowling, D.; Traverse, J. H.; Olson, R. E.; Flanagan, J.; Sodano, D.; Murayama, T.; Kawamoto, A.; Kusano, K. F.; Wollins, J.; Welt, F.; Shah, P.; Soukas, P.; Asahara, T.; Henry, T. D. Intramyocardial transplantation of autologous CD34+ stem cells for intractable angina: A phase I/IIa double-blind, randomized controlled trial. Circulation 115:3165-3172; 2007.
21. Mannheimer, C.; Camici, P.; Chester, M. R.; Collins, A. DeJongste, M.; Eliasson, T.; Follath, F.; Hellemans, I.; Herlitz, J.; Lüscher, T.; Pasic, M.; Thelle, D. The problem of chronic refractory angina. Report from de ESC joint study group on the treatment of refractory angina. Eur. Heart J. 23:355-370; 2002.

22. Moore, R. K.; Groves, D.; Bateson, S.; Barlow, P.; Hammond, C.; Leach, A. A.; Chester, M. R. Health related quality of life of patients with refractory angina before and one year after enrolment onto a refractory angina program. Eur. J. Pain 9:305-310; 2005.

23. Nasseri, B. A.; Kukucka, M.; Dandel, M.; Knosalla, C.; Potapov, E.; Lehmkuhl, H. B.; Meyer, R.; Ebell, W.; Stamm, C.; Hetzer, R. Intramyocardial delivery of bone marrow mononuclear cells and mechanical assist device implantation in patients with end-stage cardiomyopathy. Cell Transplant. 16(9):941-949; 2007.

24. Nordrehaug, J. E.; Salem, M. Treatment of chronic refractory angina pectoris-light at the end of the tunnel? Eur. Heart J. 27:1007-1009; 2006.

25. Orlic, D.; Kajstura, J.; Chimenti, S.; Jakoniuk, I.; Anderson, S. M.; Li, B.; Pickel, J.; McKay, R.; Nadal-Ginard, B.; Bodine, D. M.; Leri, A.; Anversa, P. Bone marrow cells regenerate infarcted myocardium. Nature 410:701705; 2001.

26. Patel, A. N.; Sherman, W. Cardiac stem cell therapy from bench to bedside. Cell Transplant. 16:875-878; 2007.

27. Perin, E. C.; Dohmann, H. F.; Borojevic, R.; Silva, S. A.; Sousa, A. L.; Mesquita, C. T.; Rossi, M. I.; Carvalho, A. C.; Dutra, H. S.; Dohmann, H. J.; Silva, G. V.; Belém, L.; Vivacqua, R.; Rangel, F. O.; Esporcatte, R.; Geng, Y. J.; Vaughn, W. K.; Assad, J. A.; Mesquita, E. T.; Willerson, J. T. Transendocardial, autologous bone marrow cell transplantation for severe, chronic ischemic heart failure. Circulation 107:2294-2302; 2003.

28. Perin, E. C.; Silva, G. V.; Assad, J. A.; Vela, D.; Buja, L. M.; Sousa, A. L.; Litovsky, S.; Lin, J.; Vaughn, W. K.; Coulter, S.; Fernandes, M. R.; Willerson, J. T. Comparison of intracoronary and transendocardial delivery of allogeneic mesenchymal cells in a canine model of acute myocardial infarction. J. Mol. Cell. Cardiol. 44:486-495; 2008.

29. Ramos, G. A.; Hare, J. M. Cardiac cell-based therapy: Cell types and mechanisms of actions. Cell Transplant. 16:951-961; 2007.

30. Rana, J. S.; Mannam, A.; Donnell-Fink, L.; Gervino, E. V.; Sellke, F. W.; Laham, R. J. Longevity of the placebo effect in the therapeutic angiogenesis and laser myocardial revascularization trials in patients with coronary heart disease. Am. J. Cardiol. 95:1456-1459; 2005.

31. Rosenzweig, A. Cardiac cell therapy-mixed results from mixed cells. N. Eng. J. Med. 355:1274-1277; 2006.

32. Sanberg, P. R.; Park, D. H.; Kuzmin-Nichols, N.; Cruz, E.; Hossne, Jr., N. A.; Buffolo, E.; Willing, A. E. Monocyte transplantation for neural and cardiovascular ischemia repair. J. Cell. Mol. Med.; in press.

33. Schuldt, A. J. T.; Rosen, M. R.; Gaudette, G. R.; Cohen, I. S. Repairing damaged myocardium: Evaluating cells used for cardiac regeneration. Curr. Treat. Options Cardiovasc. Med. 10:59-72; 2008.

34. Silva, S. A.; Sousa, A. L.; Haddad, A. F.; Azevedo, J. C.; Soares, V. E.; Peixoto, C. M.; Soares, A. J.; Issa, A. F.; Felipe, L. R.; Branco, R. V.; Addad, J. A.; Moreira, R. C.; Tuche, F. A.; Mesquita, C. T.; Drumond, C. C.; Junior, 
A. O.; Rochitte, C. E.; Luz, J. H.; Rabischoffisky, A.; Nogueira, F. B.; Vieira, R. B.; Junior, H. S.; Borojevic, R.; Dohmann, H. F. Autologous bone-marrow mononuclear cell transplantation after acute myocardial infarction: Comparison of two delivery techniques. Cell Transplant. 18(3):343-352; 2009.

35. Tse, H. F.; Kwong, Y. L.; Chan, J. K.; Lo, G.; Ho, C. L.; Lau, C. P. Angiogenesis in ischaemic myocardium by intramyocardial autologous bone marrow mononuclear cells implantation. Lancet 361:47-49; 2003.

36. Tse, H. F.; Siu, C. W.; Zhu, S. G.; Songyan, L.; Zhang, Q. Y.; Lai, W. H.; Kwong, Y. L.; Nicholls, J.; Lau, C. P. Paracrine effects of direct intramyocardial implantation of bone marrow derived cells to enhance neovascularization in chronic ischaemic myocardium. Eur. J. Heart Fail. 9: 747-753; 2007.

37. Vanderheyden, M.; Vercauteren, S.; Mansour, S.; Delrue, L.; Vandekerckhove, B.; Heyndrickx, G. R.; Van Haute, I.; De Bruyne, B.; Timmermans, F.; Wijns, W.; Bartunek, J. Time-dependent effects on coronary remodeling and epicardial conductance after intracoronary injection of enriched hematopoietic bone marrow stem cells in patients with previous myocardial infarction. Cell Transplant. 16(9):919-925; 2007.

38. van Ramshorst, J.; Bax, J. J.; Beeres, S. L.; DibbetsSchneider, P.; Roes, S. D.; Stokkel, M. P.; de Roos, A.;
Fibbe, W. E.; Zwaginga, J. J.; Boersma, E.; Schalij, M. J.; Atsma, D. E. Intramyocardial bone marrow cell injection for chronic myocardial ischemia. A randomized controlled trial. JAMA 301:1997-2004; 2009.

39. Womble, T. A.; Green, S.; Sanberg, P. R.; Pennypacker, K. R.; Willing, A. E. CD14+ human umbilical cord blood cells are essential for neurological recovery following MCAO. Cell Transplant. 17:485-486; 2008.

40. Womble, T. A.; Green, S. M.; Nelson, A. P.; Shahaduzzaman, M. D.; Golden, J. E.; Sanberg, P. R.; Pennypacker, K. R.; Willing, A. E. CD14 ${ }^{+}$and CD $133^{+}$human umbilical cord blood cells are essential for neurological recovery following MCAO. Cell Transplant. 18:240; 2009.

41. Yerebakan, C.; Kaminski, A.; Liebold, A.; Steinhoff, G. Safety of intramyocardial stem cell therapy for the ischemic myocardium: Results of the Rostock trial after 5-year follow-up. Cell Transplant. 16(9):935-940; 2007.

42. Yerebakan, C.; Sandica, E.; Prietz, S.; Klopsch, C.; Ugurlucan, M.; Kaminski, A.; Abdija, S.; Lorenzen, B.; Boltze, J.; Nitzsche, B.; Egger, D.; Barten, M.; Furlani, D.; Ma, N.; Vollmar, B.; Liebold, A.; Steinhoff, G. Autologous umbilical cord blood mononuclear cell transplantation preserves right ventricular function in a novel model of chronic right ventricular volume overload. Cell Transplant. 18(8):855-868; 2009. 